\title{
Constituição do campo de pesquisa em ensino de ciências no Brasil com foco nas pesquisas em educação química
}

\section{Giovana Caraballo Melatti} giovanacame@gmail.com

Universidade Tecnológica Federal do Paraná (UTFPR), Curitiba, Paraná, Brasil

Fabiana R. G. e Silva Hussein fabianah@utfpr.edu.br

Universidade Tecnológica Federal do Paraná (UTFPR), Curitiba, Paraná, Brasil

\section{RESUMO}

O objetivo deste trabalho é descrever de que modo se constituiu e vem se constituindo o campo de pesquisa em Ensino de Ciências no Brasil com foco na Educação Química. São abordados no trabalho: os aspectos históricos da constituição das áreas de Ensino de Ciências e do Ensino de Química no Brasil, os principais eventos da área de Química, bem como as instituições responsáveis por eles e a frequência e locais onde ocorrem, os principais periódicos da área de Química e suas frequências e locais de publicação, o público a que se destinam os eventos e periódicos descritos, as condições necessárias para a participação nos eventos e para publicação nos periódicos e as principais linhas temáticas das investigações. A partir da análise dos dados coletados, pode-se perceber que o campo de pesquisa em Ensino de Química é de grande importância para que haja uma melhora efetiva do processo de ensino-aprendizagem em Química no país, uma vez que é a partir da ação e do conhecimento do professor, que permanece em contínuo processo de aprimoramento profissional e que reflete acerca de sua pesquisa e de sua própria prática pedagógica, que surgem novas práticas a serem usadas em sala de aula.

PALAVRAS-CHAVE: Ensino de Ciências. Ensino de Química. Pesquisa em Ensino. Profissionalização Docente. 


\section{INTRODUÇÃO}

Para que possamos conhecer a história das pesquisas em ensino de ciências e de química no Brasil, devemos conhecer os aspectos históricos que envolvem o surgimento da química como disciplina. Segundo Filgueiras (1990), o estabelecimento de um ensino de química em nosso país ocorreu em um processo demorado e difícil, de modo que foi instituído somente no século XIX. Em decorrência da apatia de Portugal aos progressos científicos da Europa, até o início dos anos 1800, o Brasil, sendo uma colônia político, social e culturalmente dependente, experimentou pouco desenvolvimento científico.

O sistema escolar brasileiro teve início em 1549, com chegada dos primeiros jesuítas (Figura 1), e seguia um modelo que era baseado nos princípios humanistas e se voltava à formação de uma elite letrada, composta por aristocratas, sacerdotes-mestres, juízes e magistrados residentes na colônia. No ano de 1759, por exemplo, o Brasil contava com um total de 33 estabelecimentos dedicados ao ensino, entre colégios, seminários e internatos. Porém, nesse mesmo ano, o Marquês de Pombal expulsou os jesuítas do país e em decorrência disso foram geradas incertezas a respeito do processo educativo no Brasil (GILES, 2003).

Com a reforma promovida pelo Marquês de Pombal, muitas das pessoas que viviam no Brasil e que desejavam uma carreira científica ou médica foram para Portugal para estudar na Universidade de Coimbra. Segundo Carneiro (2006), no Brasil, o ensino de química nesse período era estritamente teórico e livresco, voltado ao enfoque mineralógico, e a química era vista como um apêndice da física.

Em 1772, o vice-rei do Brasil, o Marquês de Lavradio, criou no Rio de Janeiro a Academia Científica, que se destinava ao estudo das ciências e dentre as várias seções dessa academia destacou-se a existência de uma dedicada à química. Nessa academia trabalhava o português Manoel Joaquim Henriques de Paiva, autor do livro Elementos de química e farmácia, o primeiro a ter no título a palavra "química" (FILGUEIRAS, 1998).

Ezequiel Corrêa dos Santos, considerado por alguns como o mais notável farmacêutico brasileiro do século XIX, dedicou sua vida ao estudo dos componentes químicos de plantas medicinais. Foi ele o primeiro no Brasil a isolar um alcalóide, a pereirina, das cascas do pau-pereira (Geissospermum vellosii), uma árvore da família das apocináceas. Também nesse período destacou-se Vicente Coelho de Seabra Silva Telles, citado por alguns pesquisadores como um dos principais químicos do Brasil colonial e foi quem traduziu para o português o nome "química" (LIMA, 2013).

Após a invasão de Portugal por Napoleão, a corte real portuguesa mudou-se para o Brasil e, como consequência, foram realizadas ações com foco na estruturação do ensino de ciências. Segundo Chassot, esse foi um dos períodos mais grandiosos para o estabelecimento do estudo das Ciências (CHASSOT, 1996).

Um dos principais feitos de Dom João VI foi a criação do Colégio MédicoCirúrgico da Bahia, em 1808. Além disso, com a abertura dos portos, às nações amigas e a saída do Brasil do isolamento, também realizada por ele, foi criada a Biblioteca Nacional e foram instaladas as primeiras indústrias de manufaturados e tipografia no país e (ALMEIDA, 2011). 
Com a inclusão da química no currículo do curso de engenharia da Academia Real Militar, surgiram mais trabalhadores especializados nas áreas que necessitavam de um conhecimento mais profundo em ciências e química e, em decorrência dessas transformações no país, começaram a ser publicados livros impressos. Daniel Gardner foi o autor da primeira obra impressa no país, que tinha como título Syllabus, ou Compêndio das Lições de Chymica (MOTOYAMA, 2000).

Por volta do ano de 1812, com a crescente exploração do ferro, foram criados - Gabinete de Química e o Laboratório de Química Aplicada no Rio de Janeiro e, em 1818, foi fundado o Museu Real, que contava com um laboratório de química voltado para a refinação de metais preciosos (SANTOS, 2004).

Sem dúvida, o maior soberano a incentivar o progresso científico do Brasil foi D. Pedro II, que foi quem favoreceu a indústria e, por consequência, o desenvolvimento econômico do Império, entre 1831 e 1898. Nessa época, o ensino de ciências era, porém, desprestigiado, pois era baseado em metodologias de memorização e descrição e era voltado à formação de uma classe trabalhadora. Por isso, era pouco atrativo.

Alguns historiadores consideram que a história da disciplina de Química no Brasil oscilava entre as questões cotidianas e as centradas nos pressupostos científicos (LOPES, 1998). Nesse período de incertezas, foi fundado, em 1837, o Colégio Pedro II (Figura 1), no Rio de Janeiro, que servia de modelo para as escolas do Brasil e contava com disciplinas da área de ciências.

Figura 1: Colégio Dom Pedro II, em 1856.

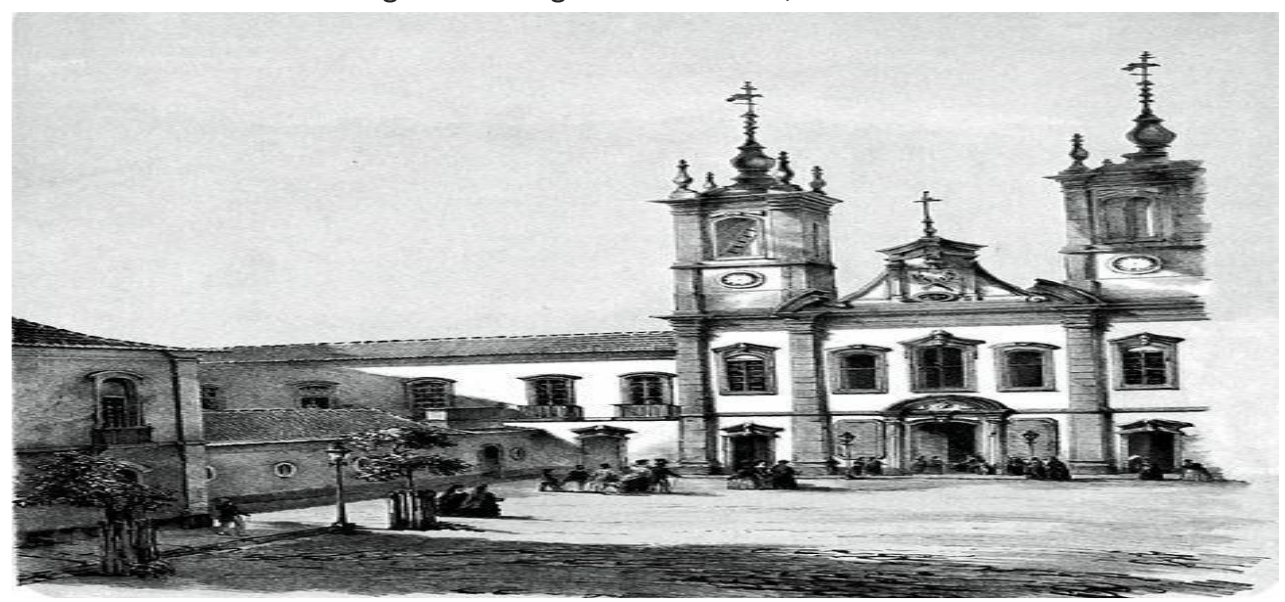

Fonte: Lima (2013).

No período republicano, foi criada a primeira escola que formaria profissionais para a indústria química: o Instituto de Química do Rio de Janeiro. Já no Ensino Médio, a química só passou a fazer parte dos currículos em 1931, com a reforma curricular de Francisco Campos (LIMA, 2013).

Em 1922, foi criada a Sociedade Brasileira de Chimica como uma das decisões do primeiro Congresso Brasileiro de Química que ocorreu naquele ano, no bojo das celebrações do primeiro centenário da Independência do Brasil. Em 1933, a grafia da palavra foi alterada de "chimica" para "química", e a Sociedade existiu até 1951. Seu primeiro presidente foi José de Freitas Machado, após a presidência provisória do professor Daniel Henninger (LIMA, 2013). 
Em 1971, com a promulgação das Leis de Diretrizes e Bases da Educação (LDB), foram criados os cursos técnicos profissionalizantes no Brasil, impondo ao ensino de química um caráter puramente técnico-científico.

A refundação da Sociedade Brasileira de Química (SBQ) aconteceu em 1977, durante a Reunião Anual da Sociedade Brasileira para o Progresso da Ciência, na Pontifícia Universidade Católica de São Paulo, e deu início a um novo ciclo (FILGUEIRAS, 1996).

Até o início dos anos oitenta, o Ensino Médio no Brasil era guiado por duas modalidades: humanístico-científica e técnica. A primeira era voltada à preparação para o nível superior e a segunda para o mercado de trabalho (LIMA, 2013).

Os anos da década de 90 do século XX foram marcados pela entrada em vigor da LDB n. 9.394 de 1996, com base na qual foram lançados o Programa de Reforma do Ensino Profissionalizante, as Diretrizes Curriculares Nacionais para o Ensino Médio (DCNEM) e os Parâmetros Curriculares Nacionais para o Ensino Médio (PCNEM).

Em se tratando do ensino de química e dos conhecimentos nele envolvidos, a proposta dos PCNEM é que sejam explicitados a multidimensionalidade, o dinamismo e o caráter epistemológico de seus conteúdos. Em 2002, foram divulgados os PCN+ (Orientações Educacionais Complementares aos Parâmetros Curriculares Nacionais), direcionados aos professores e aos gestores de escolas.

Uma das mais importantes medidas estabelecidas pelo Ministério da Educação (MEC) para a formação de professores da Educação Básica foi a publicação do Artigo 7o da Resolução n. 001/2002-CNE/CP/MEC, que determina que os cursos de licenciatura tenham identidade própria e, portanto, sejam desatrelados dos seus respectivos bacharelados.

Após o breve histórico apresentado acerca do desenvolvimento da química como disciplina no Brasil, podemos voltar as atenções para a pesquisa em ensino de ciências e de química.

\section{OS ASPECTOS HISTÓRICOS DA CONSTITUIÇÃO DO ENSINO DE CIÊNCIAS E DA EDUCAÇÃO QUÍMICA}

A Educação em Ciências (EC) surgiu no Brasil como área de estudos com demandas e objetivos próprios, ou seja, de uma didática específica das ciências, "em consonância com o movimento que ocorreu a nível mundial" (NARDI, 2007).

Antes da década de 60 do século XX não havia um campo de pesquisa em EC estruturado e consolidado como é atualmente. Fensham (2004) esclarece que os debates, as temáticas e as preocupações presentes nos primeiros trabalhos dessa área enfatizavam a experimentação como forma de melhorar o ensino de ciências.

Segundo Nardi (2015), as décadas de 60 e 70 do século passado foram férteis para que pesquisadores brasileiros das áreas de Ciências Exatas e Naturais, apoiados por colegas da Educação, Psicologia, História, Filosofia da Ciência e outras áreas do conhecimento, passassem a se preocupar em estudar mais sistematicamente o ensino e a aprendizagem das Ciências. Ainda de acordo com esse autor (2015), os fatores que contribuíram para a constituição do EC no Brasil, bem como as origens e características da pesquisa que se faz nesta área, vêm 
sendo estudados com base em vários enfoques referenciais e diversas metodologias. $O$ vasto conhecimento acumulado na área é fruto do trabalho de matemáticos, físicos, químicos e biólogos.

Para Nardi (2015), os pesquisadores têm interlocução mediante representatividade em secretarias, seções de ensino ou comissões específicas de importantes sociedades científicas tradicionais, como a Sociedade Brasileira para o Progresso da Ciência (SBPC), Sociedade Brasileira de Física (SBF), Sociedade Brasileira de Química (SBQ) e Sociedade Brasileira de Astronomia (SBA). Segundo esse autor, surgiram órgãos financiadores, como o Conselho Nacional de Desenvolvimento Científico e Tecnológico (CNPq), a Coordenação de Aperfeiçoamento de Pessoal de Nível Superior (CAPES), a Financiadora de Estudos e Projetos (FINEP) e as fundações de amparo à pesquisa de diversos estados brasileiros.

Nas décadas de 80 e 90, surgiram associações específicas de ensino, como a Sociedade Brasileira de Educação Matemática (SBEM), a Sociedade Brasileira de Ensino de Biologia (SBenBio) e a Associação Brasileira de Pesquisa em Educação em Ciências (Abrapec) (NARDI, 2015).

A área de pesquisa em Educação Química cresceu significativamente sobretudo na década de 80 . Um dos primeiros encontros foi promovido pelo professor Ático Chassot, no Rio Grande do Sul. Um momento importante desse processo foi a realização do primeiro Encontro Nacional de Ensino de Química (ENEQ), realizado no instituto de química da Universidade Estadual de Campinas (Unicamp). Nesse evento, foram definidos muitos dos termos utilizados hoje em pesquisa em Educação Química e, ainda nessa década, a pesquisa em Educação Química foi situada em uma área maior, a da Didática das Ciências (LIMA, 2013).

Informações sobre a evolução do Ensino de Ciências e do Ensino de Química ao longo da história brasileira são importantes para que se saiba quais transformações ocorreram em diferentes épocas no país e quais foram os resultados que diferentes ideologias geraram, para que, a partir desses conhecimentos, se possam sugerir novas ideias voltadas à educação. Os dados referentes à história e até aqui apresentados foram selecionados de livros, revistas e documentos que são referências nos cursos de graduação de Química.

A divulgação dos principais eventos e periódicos voltados ao Ensino da Química, apresentada a seguir, pode contribuir para uma evolução dessa área, pois a partir da melhoria da formação dos professores, pode-se promover uma melhoria da qualidade das aulas (FENSHAM, 2004).

\section{PRINCIPAIS EVENTOS E PERIÓDICOS DA ÁREA DE QUÍMICA}

A seguir, apresentamos dois quadros com a síntese dos principais eventos (Quadro 1) e periódicos (Quadro 2) da área de Química, bem como as condições necessárias para a participação neles e para a publicação nos periódicos selecionados. Para a elaboração desses quadros foram selecionados os eventos e periódicos mais divulgados nos sites das instituições de ensino superior públicas do país. 
Quadro 1: Principais eventos da área de Química

\begin{tabular}{|c|c|}
\hline Evento & Descrição \\
\hline EDEQ & $\begin{array}{c}\text { Encontro de Debates sobre o Ensino de Química: é um evento anual } \\
\text { promovido pela comunidade de Ensino de Química, especialmente } \\
\text { aquela localizada na região Sul do Brasil. Desde 1980, os EDEQs vêm } \\
\text { possibilitando o diálogo entre professores, alunos e demais } \\
\text { pesquisadores interessados na qualificação da Educação e do Ensino de } \\
\text { Química. } \\
\text { Condições para publicação ou participação: trabalhos completos de } \\
\text { acordo com formulário eletrônico (template) disponibilizado pelos } \\
\text { organizadores do evento (arquivo em formato doc ou docx). A } \\
\text { submissão está vinculada à inscrição. }\end{array}$ \\
\hline ENPEC & $\begin{array}{l}\text { Encontro Nacional de Pesquisa em Educação em Ciências: é um evento } \\
\text { bienal promovido pela Associação Brasileira de Pesquisa em Educação } \\
\text { em Ciências (ABRAPEC). O público-alvo do ENPEC é formado por } \\
\text { interessados na pesquisa em Educação em Ciências Naturais, da Saúde } \\
\text { e do Ambiente, incluindo professores-pesquisadores da Educação } \\
\text { Básica e Superior, estudantes de graduação e pós-graduação, } \\
\text { formadores de professores e pesquisadores. Tem como objetivo reunir } \\
\text { e favorecer a interação entre os pesquisadores das áreas de Ensino de } \\
\text { Física, Química, Biologia, Geociências, Ambiente, Saúde e áreas afins, } \\
\text { com a finalidade de discutir trabalhos de pesquisa recentes e tratar de } \\
\text { temas de interesse da comunidade de educadores em ciências. } \\
\text { Condição para participação ou publicação: a publicação está vinculada } \\
\text { à inscrição no evento. O trabalho de pesquisa inédita pode ser de dois } \\
\text { tipos: a) trabalho empírico em Educação em Ciências completo; ou b) } \\
\text { trabalho teórico em Educação em Ciências. Modelo Eletrônico } \\
\text { disponibilizado pelos organizadores do evento. }\end{array}$ \\
\hline ENEQ & $\begin{array}{l}\text { Encontro Nacional de Ensino de Química: é o maior e mais importante } \\
\text { evento da Divisão de Ensino da Sociedade Brasileira de Química (SBQ). } \\
\text { Acontece bienalmente e tem reunido docentes universitários, } \\
\text { professores da educação básica e alunos de vários níveis de ensino, } \\
\text { desde o médio até a pós-graduação. O ENEQ tem estimulado a área de } \\
\text { pesquisa em ensino de química e discussões de experiências de ensino e } \\
\text { formação de professores de química. } \\
\text { Condição para participação ou publicação: em suas edições, o evento } \\
\text { permite dois tipos de submissão de trabalho: a) resumo e b) trabalho } \\
\text { completo (ambos em arquivo formato PDF). As regras e critérios para } \\
\text { publicação são divulgados em formulário eletrônico. A submissão está } \\
\text { atrelada à inscrição no evento, e os trabalhos devem ser inéditos. }\end{array}$ \\
\hline RASBQ & $\begin{array}{l}\text { Reunião Anual da Sociedade Brasileira de Química: a SBQ (Sociedade } \\
\text { Brasileira de Química) realiza sua reunião anual, geralmente, na última } \\
\text { semana de maio. É o maior evento em Química da América Latina, de } \\
\text { que participam cerca de } 2500 \text { pesquisadores, incluindo professores e } \\
\text { estudantes, com apresentações de cerca de } 2200 \text { comunicações } \\
\text { distribuídas por áreas de atuação nas divisões científicas. } \\
\text { Condição para participação ou publicação: a submissão de trabalhos } \\
\text { inéditos está vinculada à inscrição. Os trabalhos enviados seguem } \\
\text { modelo de resumo disponível na página do evento e podem ser } \\
\text { redigidos em língua portuguesa ou inglesa. }\end{array}$ \\
\hline
\end{tabular}

Fonte: Autoria própria (2017). 
Quadro 2: principais periódicos da área de Química

\begin{tabular}{|c|c|}
\hline Periódico & Descrição \\
\hline $\begin{array}{l}\text { Ciência \& } \\
\text { Educação }\end{array}$ & $\begin{array}{l}\text { É um periódico trimestral, com edições nos meses de março, junho, } \\
\text { setembro e dezembro, e destina-se à publicação de trabalhos científicos } \\
\text { originais nas áreas de educação em ciências, educação matemática e } \\
\text { outras afins. Seu título abreviado é Ciênc. educ. (Bauru). } \\
\text { A revista é financiada pelo Programa de Pós-Graduação em Educação } \\
\text { para a Ciência da Faculdade de Ciências da Unesp, campus de Bauru, } \\
\text { pelo Conselho Nacional de Desenvolvimento Científico e Tecnológico } \\
\text { (CNPq), pela Coordenação de Aperfeiçoamento de Pessoal de Nível } \\
\text { Superior (CAPES) e pela Pró-Reitoria de Pesquisa (PROPE) da } \\
\text { Universidade Estadual Paulista "Júlio de Mesquita Filho" (UNESP). Tem } \\
\text { como missão publicar artigos científicos sobre resultados de pesquisas } \\
\text { empíricas ou teóricas e ensaios originais sobre temas relacionados à } \\
\text { Educação Científica. Entende-se por pesquisa em Educação Científica as } \\
\text { investigações que geram conhecimentos, por exemplo, sobre o ensino e } \\
\text { a aprendizagem de Ciências, Física, Química, Biologia, Geociências, } \\
\text { Educação Ambiental, Matemática e áreas afins. } \\
\text { Condição para participação ou publicação: os trabalhos inéditos devem } \\
\text { ter caráter interdisciplinar e introduzir novidades no campo do } \\
\text { conhecimento. Artigos empíricos devem conter dados que referenciem } \\
\text { novos desdobramentos para o conhecimento e aplicação em contextos. } \\
\text { Submissão on-line. }\end{array}$ \\
\hline $\begin{array}{c}\text { Ensaio } \\
\text { Pesquisa em } \\
\text { Educação em } \\
\text { Ciências }\end{array}$ & $\begin{array}{l}\text { A Revista Ensaio Pesquisa em Educação em Ciências é publicação do } \\
\text { Centro de Ensino de Ciências e Matemática (CECIMIG) } \\
\text { (www.fae.ufmg/cecimig), órgão de pesquisa e extensão no ensino de } \\
\text { ciências da Faculdade de Educação e do Programa de Pós-Graduação } \\
\text { em Educação, ambos da UFMG. Publica artigos de pesquisa inéditos } \\
\text { (relatos de pesquisa empírica ou ensaios teóricos) de interesse ao } \\
\text { campo da Educação em Ciências, atendendo a um público de } \\
\text { pesquisadores e estudantes de pós-graduação das áreas de Educação } \\
\text { Científica, Ensino das Ciências da Natureza (Biologia, Física, Química, } \\
\text { Geociências e Astronomia), da Educação em Saúde e Ambiental e, } \\
\text { ainda, a um público de formação inicial e continuada das licenciaturas } \\
\text { no campo das Ciências Naturais, de áreas afins e outros profissionais da } \\
\text { Educação Básica envolvidos com o ensino em ciências. A revista está em } \\
\text { seu 16o volume (2016) e teve seu primeiro número editado no segundo } \\
\text { semestre de 1999. Atualmente, é disponibilizada em formato } \\
\text { eletrônico, com três números por ano (lançados, respectivamente, em } \\
\text { abril, agosto e dezembro). Os trabalhos submetidos à publicação devem } \\
\text { ser inéditos e não podem estar sendo analisados em outro veículo. } \\
\text { Comunicações feitas em congressos podem ser submetidas desde que } \\
\text { ampliado seu escopo, evitando repetições de trabalhos completos } \\
\text { publicados em anais de eventos. } \\
\text { Condição para participação ou publicação: os trabalhos inéditos devem } \\
\text { ter caráter interdisciplinar e introduzir novidades no campo do } \\
\text { conhecimento. Artigos empíricos devem conter dados que referenciem } \\
\text { novos desdobramentos para o conhecimento e aplicação em contextos. } \\
\text { Submissão on-line. }\end{array}$ \\
\hline $\begin{array}{c}\text { Educação em } \\
\text { Foco }\end{array}$ & $\begin{array}{l}\text { A revista, órgão oficial da Faculdade de Educação da Universidade } \\
\text { Federal de Juiz de Fora (UFJF), cumpre papel relevante na instituição. } \\
\text { Ela é instrumento divulgador da produção dos seus núcleos de } \\
\text { pesquisa, bem como do seu programa de pós-graduação de mestrado e } \\
\text { doutorado. Da mesma forma, tem se constituído como interface com a } \\
\text { produção científica de outras instituições nacionais e internacionais. }\end{array}$ \\
\hline
\end{tabular}




\begin{tabular}{|c|c|}
\hline Periódico & Descrição \\
\hline & $\begin{array}{l}\text { Graças ao periódico, é dada visibilidade à produção de pesquisa da } \\
\text { instituição e dissertações defendidas, bem como de futuras teses, e são } \\
\text { estabelecidos elos com outras instituições. O público-alvo e real são os } \\
\text { pesquisadores/professores e estudantes da área de Ciências Humanas } \\
\text { em geral, especialmente o público dos programas de pós-graduação em } \\
\text { educação. Busca-se a comunicação com boa parte dos programas de } \\
\text { pós-graduação em educação nacionais e alguns internacionais, o que } \\
\text { resulta em doação da coleção completa da revista às bibliotecas desses } \\
\text { programas. Publica três números por ano. } \\
\text { Condição para participação ou publicação: submissão on-line. Os } \\
\text { artigos devem estar em conformidade com o perfil da revista. Arquivo } \\
\text { deve ser enviado em Word (Windows). }\end{array}$ \\
\hline Redequim & $\begin{array}{l}\text { A Revista Debates em Ensino de Química (REDEQUIM) é semestral para } \\
\text { publicação de artigos na área de Ensino de Química. } \\
\text { Condição para participação ou publicação: submissão on-line. Os } \\
\text { artigos seguem a formatação de template no formato Word (Windows), } \\
\text { disponível na página. }\end{array}$ \\
\hline $\begin{array}{c}\text { Revista } \\
\text { Brasileira de } \\
\text { Pesquisa em } \\
\text { Educação em } \\
\text { Ciências } \\
\text { (RBPEC) }\end{array}$ & $\begin{array}{c}\text { É uma publicação da Associação Brasileira de Pesquisa em Educação em } \\
\text { Ciências (ABRAPEC) e tem como objetivo disseminar resultados e } \\
\text { reflexões advindos de investigações conduzidas na área de Educação } \\
\text { em Ciências. } \\
\text { Qualquer submissão que contenha relato de experiência ou } \\
\text { apresentação de material instrucional de variados tipos não será } \\
\text { encaminhada para avaliação. } \\
\text { A Revista Brasileira de Pesquisa em Educação em Ciências tem como } \\
\text { público-alvo pesquisadores, estudantes de pós-graduação e de } \\
\text { licenciatura da área de Educação em Ciências. } \\
\text { Artigos originais são aqueles que não foram publicados em outros } \\
\text { meios, podendo ser originados de trabalhos acadêmicos e apresentados } \\
\text { em congressos científicos, mas nunca ser (total ou parcialmente) igual a } \\
\text { esses. Em outras palavras, é preciso que o artigo seja claramente uma } \\
\text { expansão em relação ao trabalho inicial. Qualquer submissão } \\
\text { identificada como publicada anteriormente em outro meio ou cujo } \\
\text { texto corresponder ao de trabalho apresentado em congresso científico } \\
\text { - isto é, que possa ser caracterizada como autoplágio - não será } \\
\text { encaminhada para avaliação. } \\
\text { A Revista Brasileira de Pesquisa em Educação em Ciências foi criada em } \\
\text { 2001 e lançada oficialmente no III Encontro Nacional de Pesquisa em } \\
\text { Educação em Ciências (III ENPEC, Atibaia, SP, } 7 \text { a } 10 \text { de novembro de } \\
\text { 2001). Desde então, tem sido publicada regularmente, com } \\
\text { periodicidade quadrimestral. } \\
\text { Condição para participação ou publicação: submissão on-line. Os } \\
\text { artigos devem seguir modelo de formatação disponível na página e } \\
\text { formato de arquivo PDF. Aceita-se trabalhos já apresentados em } \\
\text { eventos. Artigos enviados não podem estar em análise em outras } \\
\text { revistas. }\end{array}$ \\
\hline QNEsC & $\begin{array}{l}\text { A Revista Química Nova na Escola (QNEsc), com uma periodicidade } \\
\text { trimestral, propõe-se a subsidiar o trabalho, a formação e a atualização } \\
\text { da comunidade do Ensino de Química brasileiro. QNEsc integra-se à } \\
\text { linha editorial da Sociedade Brasileira de Química, que publica também } \\
\text { a revista Química Nova e o Journal of the Brazillian Chemical Society. } \\
\text { Química Nova na Escola é um espaço aberto ao educador, suscitando } \\
\text { debates e reflexões sobre o ensino e a aprendizagem de química. Assim, } \\
\text { contribui para a tarefa fundamental de formar verdadeiros cidadãos. }\end{array}$ \\
\hline
\end{tabular}




\begin{tabular}{|c|c|}
\hline Periódico & Descrição \\
\hline & $\begin{array}{l}\text { Nesse sentido, a Divisão de Ensino disponibiliza em seu portal, na } \\
\text { íntegra, e de forma totalmente gratuita, todos os artigos publicados no } \\
\text { formato PDF. Estão disponíveis também os Cadernos Temáticos } \\
\text { publicados desde } 2001 \text { pela Divisão de Ensino. } \\
\text { Condição para participação e publicação: os trabalhos deverão ser } \\
\text { digitados em página A4, espaço duplo, fonte tipo Times Roman, } \\
\text { margens } 2,5 \text {, devendo ter no máximo o número de páginas especificado } \\
\text { para a seção da revista à qual são submetidos. Na primeira página, } \\
\text { deverá conter o título do trabalho e um resumo do artigo com, no } \\
\text { máximo, } 1000 \text { caracteres (espaços inclusos), e a indicação de três } \\
\text { palavras-chave, seguidos de suas traduções para a linha inglesa, } \\
\text { incluindo o título. }\end{array}$ \\
\hline $\begin{array}{l}\text { Investigações } \\
\text { em Ensino de } \\
\text { Ciências } \\
\text { (IENCI) }\end{array}$ & $\begin{array}{l}\text { É uma revista voltada exclusivamente para a pesquisa na área de } \\
\text { ensino/aprendizagem de ciências (Física, Química, Biologia ou Ciências } \\
\text { Naturais quando enfocadas de maneira integrada). Somente são aceitos } \\
\text { para publicação artigos de: } 1 \text { ) investigação (i.e., com questão de } \\
\text { pesquisa bem definida, com fundamentação teórica/metodológica e } \\
\text { referências a estudos relacionados); } 2 \text { ) revisão da literatura em certa } \\
\text { área de pesquisa em ensino/aprendizagem de ciências, em um período } \\
\text { de tempo não inferior a dez anos, abrangendo os principais periódicos } \\
\text { da área nos níveis nacional e internacional; 3) fundamentação teórica } \\
\text { com implicações claras para a investigação em ensino de ciências, } \\
\text { envolvendo referenciais ainda não amplamente difundidos na área; } 4 \text { ) } \\
\text { metodologia da pesquisa educacional com relevância direta para a } \\
\text { investigação em ensino de ciências; } 5 \text { ) crítica (ou defesa) e comentários } \\
\text { sobre artigos publicados na própria revista. Relatos de experiências, } \\
\text { propostas didáticas não associadas a pesquisas, e artigos somente de } \\
\text { levantamento de opiniões, de concepções ou de dados numéricos, por } \\
\text { meio de questionários ou entrevistas, não serão considerados para } \\
\text { arbitragem. } \\
\text { A periodicidade é de três números por ano, em abril, agosto e } \\
\text { dezembro. O apoio é do Instituto de Física da Universidade Federal do } \\
\text { Rio Grande do Sul, em Porto Alegre, Brasil. A distribuição é, } \\
\text { principalmente, eletrônica, via World Wide Web. } \\
\text { denondição para participação ou publicação: a submissão segue modelo } \\
\text { sendo submetido a outros periódicos e, no caso de possuir mais de três } \\
\text { autores, deve conter uma justificativa da multiplicidade de } \\
\text { autores. Submissão on-line. }\end{array}$ \\
\hline $\begin{array}{c}\text { Ciência \& } \\
\text { Ensino }\end{array}$ & $\begin{array}{l}\text { Destinada a professores de ciências do Ensino Fundamental e Médio e } \\
\text { seus formadores, publica, nas suas diversas seções, textos submetidos e } \\
\text { também escritos a convite dos Editores da revista. Seu objetivo } \\
\text { principal é contribuir para a leitura do professor. Além dos dois } \\
\text { números regulares que compõem cada volume anual da revista, a } \\
\text { Ciência \& Ensino publica números extras especiais temáticos, a partir de } \\
\text { propostas submetidas por organizadores aos Editores. É publicada } \\
\text { semestralmente, sempre em junho e dezembro. Números extras } \\
\text { temáticos podem ser publicados em qualquer data. } \\
\text { Condição para participação ou publicação: submissão on-line. O } \\
\text { trabalho deve estar em conformidade com o perfil editorial da revista. } \\
\text { O modelo de template está disponível na página para formatação. }\end{array}$ \\
\hline
\end{tabular}




\section{AS PRINCIPAIS LINHAS TEMÁTICAS DAS INVESTIGAÇÕES}

Segundo Schnetzler (2002), a pesquisa em Ensino de Química no Brasil se desenvolveu devido a seis grandes marcos, que serão descritos a seguir.

1. A constituição da divisão de ensino na Sociedade Brasileira de Química: criada em 1988 em um dos encontros realizados pela SBQ, no qual se possibilitou a discussão sobre a decadência do ensino dessa ciência no Brasil, levando à constatação de que providências deveriam ser tomadas.

2. Os encontros nacionais e regionais do Ensino de Química: ganharam força e público desde os anos 80 , promovendo debates, discussões e novos produtos para a comunidade de ensino no Brasil.

3. A seção de educação nas reuniões anuais da SBQ e na Revista Química Nova: promoveu a divulgação de trabalhos e autores que se interessavam pelo assunto e tinham muito a contribuir para o desenvolvimento das linhas temáticas que estavam se formando nos cursos de pós-graduação distribuídos pelo país.

4. Projetos da divisão de ensino e a QNESQ: possibilitaram a divulgação ampla da causa, facilitando a conquista de novos parceiros e financiadores, expandindo a realização de encontros e cursos voltados à formação de professores, bem como a abertura da Revista Química Nova na Escola.

5. A formação de Mestres e Doutores em Ensino de Química: aconteceu de forma significativa entre os anos 90 e 2001, devido a toda essa divulgação e concentração na valoração dessa modalidade de pesquisa (SCHNETZLER, 2002).

Com base em um levantamento realizado pela autora, dentre as principais Instituições de Ensino do País, responsáveis pela formação de Mestres e Doutores na área de Ensino em Química, as principais linhas temáticas que se desenvolveram desde então foram:

Ensino e aprendizagem de conceitos científicos - aspectos cognitivos, sociais e afetivos envolvidos no ensino e na aprendizagem de conceitos científicos em diferentes níveis de ensino; ambientes de aprendizagem; aprendizagem colaborativa; modelos e modelagem na Educação em Ciências/Química; ensino por investigação; experimentação e aprendizagem de habilidades científicas.

Formação de professores de Ciências/Química - análise de programas e políticas de formação inicial e formação continuada; avaliação de modelos e práticas de formação de professores para diferentes níveis e modalidades de ensino; desenvolvimento profissional de professores; pesquisa e formação de professores; saberes docentes e práticas reflexivas.

História, Filosofia e Sociologia da Ciência na Educação em Ciências/Química História e Filosofia da Ciência; Epistemologia e Educação em Ciências; natureza da ciência; Estudos da Ciência; Sociologia do conhecimento científico.

Educação em espaços não formais e divulgação científica - história, políticas e práticas de divulgação científica e suas relações com a Educação em Ciências/Química; relações entre comunicação e educação; educação em museus e centros de ciências; divulgação científica e inclusão social.

Tecnologias da informação e comunicação na Educação em Ciências/Química - desenho e avaliação de recursos e ambientes mediados por tecnologias para o 
ensino de Ciências/Química; metodologias de pesquisa baseada em design; materiais multimídia e hipermídia; recursos audiovisuais e educação a distância.

Educação Ambiental e Educação em Ciências/Química - educação ambiental e educação em ciências; educação para o desenvolvimento sustentável; educação para a sustentabilidade.

Educação em Saúde e Educação em Ciências - educação em saúde, educação popular em saúde, promoção da saúde, formação docente e profissional em saúde.

Linguagens, discurso e Educação de Ciências/Química - abordagens discursivas, argumentação, interações discursivas, leitura e escrita no ensino de ciências.

Alfabetização científica e tecnológica, abordagens CTS e Educação de Ciências/Química - relações entre ciência, tecnologia e sociedade; questões sociocientíficas, temas controversos, letramento científico.

Currículos - desenvolvimento de currículos, políticas de currículo; seleção e organização do conhecimento escolar; história das disciplinas; reformas curriculares, suas implementações e avaliações; inovação educacional; currículos e cultura.

Avaliação na Educação em Ciências/Química - aspectos metodológicos da avaliação em ciências; abordagens e práticas de avaliação de programas; indicadores de desempenho e avaliação; avaliação de sistema; estudos comparativos internacionais.

Diversidade, multiculturalismo e Educação em Ciências/Química - relações entre ensino de ciências e temas tais como inclusão, gênero, raça, etnia, classe; educação indígena e de demais grupos sociais específicos, políticas de ação afirmativa.

Processos e materiais educativos na Educação em Ciências/Química - análise de dinâmicas para trabalhos em grupo (por exemplo, rodas de conversa, debates, dramatização, etc.), sequências didáticas, livros didáticos, jogos educativos; atividades práticas.

Políticas educacionais e Educação em Ciências/Química - histórico, análise e impactos de políticas públicas para a Educação em Ciências/Química em diferentes níveis e modalidades de ensino; legislação educacional e ensino de ciências; financiamento de ações educacionais; fomento à pesquisa em educação científica e tecnológica; políticas educacionais e políticas de desenvolvimento e inovação social, científica e tecnológica; programas de vocação e iniciação científica; programas de incentivo à docência; formação de professores de Ciências/Química em nível de pós-graduação, lato e stricto sensu; Olimpíadas de Química.

Questões teóricas e metodológicas da pesquisa em Educação em Ciências/Química - considerações epistemológicas sobre a natureza da pesquisa; referenciais teóricos da pesquisa em Educação em ciências/Química; Educação em Ciências/Química como campo científico; reflexões acerca de metodologias e métodos de pesquisa.

6. Desenvolvimento de projetos de ensino e publicação de livros na área do Ensino de Química: serviram de suporte e estímulo para novos projetos e compreensão dos rumos que o ensino e as linhas temáticas deveriam seguir. 
Vários projetos de Ensino de Química foram desenvolvidos e publicados nesses últimos 15 anos, constituindo importante alternativa para professores que, até então, só dispunham de livros didáticos pouco adequados a um processo significativo de ensino-aprendizagem, conforme evidenciam as inúmeras pesquisas realizadas sobre tais materiais (SCHNETZLER, 2002).

\section{NORMAS PARA SUBMISSÃO - ASPECTOS ÉTICOS}

Quando se discute os aspectos éticos para submissão de trabalhos, as normas não se alteram muito, seja em periódicos e/ou eventos científicos. Os trabalhos encaminhados devem ser originais, isto é, devem ser inéditos (não podem ter sido publicados em outros meios). Estes podem ter se originado de trabalhos acadêmicos e trabalhos apresentados em congressos científicos, mas nunca ser (total ou parcialmente) iguais a eles. Sendo assim, é preciso que o artigo seja claramente uma expansão do trabalho inicial. Todo artigo em submissão que for identificado como publicado anteriormente, em outro meio ou cujo texto corresponder ao de trabalho apresentado em congresso científico - isto é, que possa ser caracterizado como autoplágio - não será encaminhado para avaliação.

Ainda, considerando os aspectos éticos, é essencial que:

a) nenhum dado, texto ou ideia de outrem seja apresentado como se fosse de autoria do(s) autor(es), isto é, o artigo não pode conter plágio. Para evitar que isto aconteça, é obrigatório fazer referência à publicação original do dado, texto, ou ideia, independente de ele ter sido citado literalmente, resumido ou parafraseado. No caso de citação literal, o(s) autor(es) deve(m) usar aspas. Observação: o periódico pode usar software para identificação de plágio.

b) nenhum dado, imagem ou gráfico tenha sido fabricado ou manipulado de forma a dar suporte a alguma conclusão do(s) autor(es).

c) o(s) autor(es) não cometam autoplágio, isto é, não usem partes substanciais de seus trabalhos prévios no manuscrito.

d) que o estudo tenha sido concluído quando da submissão do manuscrito no caso de trabalhos empíricos.

Antes de submeter o manuscrito, o(s) autor(es) deve $(\mathrm{m})$ verificar a conformidade da submissão em relação a todos os seguintes itens.

- O texto não está sendo avaliado em outros periódicos concomitantemente.

- $\mathrm{O}$ arquivo não apresenta nenhum dado que permita a identificação dos autores.

- A contribuição é original, inédita e de autoria dos autores.

- O texto deve seguir os padrões de estilo e requisitos bibliográficos descritos em Diretrizes para Autores, segundo o modelo ali apresentado.

Quanto às publicações, destacamos aqui a criação e a divulgação da Revista Química Nova na Escola, que teve uma participação essencial no processo de evolução e divulgação dos conceitos em Ensino de Química.

Como instrumento de divulgação, troca das concepções, metodologias e estratégias para o Ensino de Química, a QNEsc constituiu-se como um importante 
recurso na difusão e no aprofundamento dos discursos da comunidade de pesquisadores em ensino nos últimos vinte anos, e a seção "Conceitos Científicos", que nasceu junto com a revista, veio para discutir os conceitos básicos da química, na tentativa de evidenciar a relação dos conhecimentos químicos básicos com a estrutura conceitual da ciência e com o desenvolvimento histórico, como também de discutir as principais dificuldades e alternativas para o Ensino de Química.

Em seus vinte anos de existência (maio/1995 a maio/2015), foram publicados 35 artigos em 56 volumes da QNEsc, não havendo regularidade/continuidade na publicação dos artigos da seção após o volume de maio de 2001. Alguns artigos apresentam a discussão de conceitos educacionais e científicos de uma forma mais ampla, enquanto outros realizam a discussão associada a uma proposta teóricometodológica específica.

No levantamento feito por Rozana Gomes de Abreu e Nathália Barbosa SathlerLenz Cesar, observou-se o desenvolvimento da seção "Conceitos Científicos" em três momentos, a saber.

1. Versou nos campos filosófico e epistemológico para o campo mais concreto da prática, voltado para uma visão metodológica daquilo que potencializaria a aprendizagem no "chão da escola".

2. Caracterizou-se por uma busca do incremento na utilização de experiências e outras propostas de ação, como jogos didáticos, uma vez que essas iniciativas são entendidas não só como uma estratégia motivadora, mas também como ação que acaba por se traduzir em uma melhor compreensão por parte dos alunos.

3. Movimento de ampliação do foco da Educação Básica para um diálogo com - Ensino Superior, talvez em uma tentativa de superar a dicotomia universidade/escola, ampliar a reflexão sobre o ensino e seus atores e potencializar o diálogo com as áreas de História e Filosofia da Ciência nos cursos de licenciatura e formação continuada, espaços tidos como o principal lócus de preparação e formação daqueles que virão a atuar na Educação Básica.

\section{CONSIDERAÇÕES FINAIS}

As escolhas de marcos históricos são sempre arbitrárias, em qualquer campo de estudo, e dependem sempre do olhar de quem faz as a seleção das informações e da interpretação que faz dos dados. Neste trabalho, objetivou-se resgatar um pouco da história brasileira do ensino de ciências e do ensino de química e, além disso, também visou-se informar aos leitores sobre os principais eventos e periódicos da área de Química, para que possam divulgar as informações aos seus conhecidos ou aprimorar suas formações.

O conhecimento acerca dos marcos históricos são importantes para que se perceba que a transmissão de informações mantém relatos de experiências que geraram resultados positivos e negativos, visando aprimorar o futuro. Atualmente, existem no Brasil diversos cursos de Química de nível médio e de nível superior e muitas instituições já contam até com cursos de pós-graduação, mestrado e doutorado voltados para a área. Além disso, existem programas destinados às práticas laboratoriais e à iniciação científica. 
Praticamente todas as instituições do Brasil que oferecem cursos de formação de professores já se adequaram à exigência do artigo 70 da Resolução no 001/2002-CNE/CP/MEC, que determina que os Cursos de Licenciatura devem ter identidade própria. Desse modo, esperamos que os cursos de Licenciaturas em Química difundidos pelo país possam desempenhar genuinamente o seu papel, que é o de formar professores competentes e habilitados a dar significado ao aprendizado de Química para nossos estudantes do Ensino Básico.

É evidente que a evolução do ensino e da pesquisa proporcionou, além da melhoria e do aumento da qualidade, suporte para o Ensino de Química. No entanto, ainda se trata de uma área em desenvolvimento e, tão logo, muitas outras temáticas e linhas de pesquisa deverão ser desenvolvidas para que, cada vez mais, os profissionais estejam preparados para realização de um trabalho contextualizado e fortalecido por pesquisas e referenciais teóricos. 


\title{
Constitution of the field of research in science education in Brazil focusing on research in chemical education
}

\begin{abstract}
The purpose of this article is to describe how the field of research in Science Teaching in Brazil with the focus on Chemical Education was constituted and has been constituted. The following aspects are covered: the historical aspects of the constitution of the areas of Science Teaching and Chemistry Teaching in Brazil, the main events in the Chemistry area, as well as the institutions responsible for them and the frequency and locations where they occur, Of the Chemistry area and its frequencies and places of publication, the intended audience for the events and periodicals described, the necessary conditions for participation in the events and for publication in the periodicals and the main thematic lines of the investigations. From the analysis of the data collected, it can be seen that the field of research in Teaching Chemistry is of great importance for there to be an effective improvement of the teaching-learning process in Chemistry in the country, since it is from the action And of the teacher's knowledge, which remains in a continuous process of professional improvement and that reflects on his research and his own pedagogical practice, that new practices emerge to be used in the classroom.
\end{abstract}

KEYWORDS: Science teaching. Chemistry teaching. Research in teaching. Teacher professionalization. 


\section{REFERÊNCIAS}

ABREU, R.G; CÉZAR, N.T.B.S.L. Conceitos Científicos em Destaque: Enfoques da Comunidade Disciplinar de Ensino de Química na QNEsc. Revista Química Nova na Escola, v.37, n. Especial 2, p. 161-165, São Paulo -SP, Dez. 2015.

ALMEIDA, M.R; PINTO A.C. Uma breve história da química brasileira. Química Nova, v.18, n.6, p.41-44, 2011.

ASSOCIAÇÃO BRASILEIRA DE ENSINO EM CIÊNCIAS (ABRAPEC). Linhas Temáticas. Disponível em: <http://www.abrapec.ufsc.br> Acesso em: 7 mai. 2016.

ASSOCIAÇÃO BRASILEIRA DE PESQUISA EM EDUCAÇÃO EM CIÊNCIAS. X ENPEC. Disponível em: http://abrapecnet.org.br/wordpress/pb/x-enpec/. Acesso em: 8 mai. 2016.

CHASSOT, A. I. Uma história da educação química brasileira: sobre seu início discutível apenas a partir dos conquistadores. Episteme, v.1, n. 2, p. 129-146, 1996.

ENCONTRO DE DEBATES SOBRE O ENSINO DE QUÍMICA. Primeira Circular: Divulgação do 360 EDEQ. Disponível em:

<http://36edeq.edeq.com.br/index.html> Acesso em: 8 mai. 2016.

ENCONTRO NACIONAL DO ENSINO DE QUÍMICA. Encontro Nacional Do Ensino De Química. Disponível em: <http://www.eneq2016.ufsc.br>. Acesso em: 8 mai. 2016.

ENCONTRO NACIONAL DE PESQUISA EM EDUCAÇÃO E EM CIÊNCIAS (ENPEC). IX Encontro Nacional de Pesquisa em Educação e em Ciências. Disponível em: <http://www.nutes.ufrj.br/abrapec/ixenpec/>. Acesso em 16 mai. 2016

FERRI, M. G.; MOTOYAMA, S. História das ciências no Brasil. São Paulo: EDUSP, 1979. p. $93-110,2013$

IFPR. Ciência \& Ensino. Disponível em:

<http://prc.ifsp.edu.br/ojs/index.php/cienciae ensino>. Acesso em 8 mai. 2016.

LIMA, JOSÉ. Do período colonial aos nossos dias: uma breve história do Ensino de 
MORTIMER, E. F.; Machado, A.H.; Romanelli, L.; A Evolução do Ensino de Química no Brasil. Química Nova, . 23, p. 27, 2000.

PORTO, P. A.; et. al. O ENEQ e a pesquisa em ensino de Química. Química Nova na Escola, v. 37, p. 3, 2015.

QNESC. Revista Química Nova na Escola. Disponível em:

<http://qnesc.sbq.org.br/index_site.php> Acesso em 9 mai. 2016.

QUEIROZ. A; MELO, C. Etnografia na pesquisa em ensino de ciências no Brasil: análise de dois referenciais teórico-metodológicos importantes no campo. França E, S; Munford, D., VII.

REVISTA DEBATES EM ENSINO DE QUÍMICA . Submissão de artigo. Disponível em: <http://www.redequim.com.br/> Acesso em 9 mai. 2016.

REVISTA BRASILEIRA DE PESQUISA EM EDUCAÇÃO EM CIÊNCIAS. Mudanças nas condições para submissão. Disponível em: <http://revistas.if.usp.br/rbpec>

SCHNETZLER, R. P. A pesquisa em Ensino de Química no Brasil. Química Nova, v. 25, p. 14, 2002.

SOCIEDADE BRASIELIRA DE QUÍMICA. Página inicial. Disponível em: http://www.sbq.org.br/39ra/. Acesso em 8 mai. 2016.

UEMG. Educação em Foco. Disponível em: $<$ http://www.uemg.br/openjournal/index.php/ educacaoemfoco>. Acesso em 9 mai. 2016.

UFMG. Ensaio Pesquisa em Educação em Ciências. Disponível em: http://www.portal.fae.ufmg.br/seer/index.php/ensaio. Acesso em 8 mai. 2016.

UFRGS. Investigações em Ensino de Ciências. Disponível em:

http://www.if.ufrgs.br/ienci/?go=home . Acesso em 9 mai. 2016. 
Recebido: 29 mai. 2017

Aprovado: 21 jul. 201

DOI: $10.3895 /$ actio.v2n1.6722

Como citar:

MELATTI, G. C; HUSSEIN, F. R. G. S. da. Constituição do campo de pesquisa em ensino de ciências no Brasil com foco nas pesquisas em educação química. ACTIO, Curitiba, v. 2, n. 1, p. 23-40, jan./jul. 2017. Disponível em: <https://periodicos.utfpr.edu.br/actio>. Acesso em: XXX.

Correspondência:

Giovana Caraballo Melatti

Rua Epaminondas Santos, 1938, Bairro Alto, Curitiba, Paraná, Brasil.

Direito autoral: Este artigo está licenciado sob os termos da Licença Creative Commons-Atribuição 4.0 Internacional.

(c) (1) 